\title{
Marketing and innovative aspects of the research of the competitiveness of countries in the grain market (for example, wheat)
}

\author{
Ilkhom Umarov ${ }^{1, *}$, Nursultan Shurenov ${ }^{1}$, Zhanna Kozhamkulova $^{1}$, Kyz-Zhibek Abisheva ${ }^{1}$ \\ ${ }^{1}$ Al-Farabi Kazakh National University, al-Farabi Ave. 71, 050040 Almaty, Republic of Kazakhstan
}

\begin{abstract}
This article discusses the key aspects of the development of grain production in countries exporting wheat and using innovations in its production. As you know, wheat is a strategic product of many countries and many sectors of the economy depend on its production. In terms of competitiveness, wheat ranks first among other agricultural products in terms of pricing and planting area. The yield and price of wheat are affected by many factors that are considered in this article. In order to analyze all aspects affecting the yield and price of wheat, we had to study the literature on the wheat market and its production. In addition, an analysis was made of the trends in the development of grain production in countries producing and exporting wheat. This study has collected data from the last 5 years for world countries exporting wheat.
\end{abstract}

\section{Introduction}

According to the report of the Food and Agricultural Organization of UN for May 2019, the demand for wheat in the world remains unchanged, and the main wheat exporters in the world [1] provide grain markets. The Top 10 exporters of wheat in the world include Russia, the EU, USA, Canada Australia, Ukraine, Argentina, Kazakhstan, Turkey, and India. However, the top 10 wheat producers in the world include the EU, China, India, Russia, the USA, Canada, Pakistan, Ukraine, Australia and Turkey. China, Argentina and Pakistan are not among the Top 10 exporters of wheat in the world, although they produce wheat no less than those countries that export it.

Wheat is a source of flour and it is used in almost many sectors of the economy, and its processed products are used in animal husbandry, poultry farming, the alcohol industry, and most importantly, bread is made from it, which is an integral product in human life. Food security, both globally and in the context of individual countries, largely depends on the level of grain consumption per capita. Market demand is formed not only for food grain as a whole, but also for its individual types (soft and hard varieties), as well as the type of grain of different quality and for different purposes. The grain market is an important element in the system of agricultural food markets. Export grain is also an indicator of countries'

${ }^{*}$ Corresponding author: rilyas@ mail.ru 
competitiveness in food supply. Wheat is the main commodity type of grain - in world production; its share is about $40 \%$, and in world trade - 50\%. Therefore, today there is a tendency to increase wheat production in the world, the use of new technologies and innovations for its production.

\section{Survey of the Literature and Trends}

Studies that examine trends in the development of wheat production in the world and the reasons that affect the price of wheat globally. The analysis conducted in this study will provide an understanding of the growth and decline trends in wheat prices, as well as identify the most competitive countries in the grain market in the world. Table 1 presents the Top 10 countries producing wheat in the world.

Table 1. TOP-10 countries of wheat producers in the world for 2015-2019, million tons.

\begin{tabular}{l|c|c|c|c|c}
\hline & 2015 & 2016 & 2017 & 2018 & 2019 \\
\hline EU & 155 & 156 & 149 & 136,9 & 154 \\
\hline China & 130,2 & 131,7 & 134,3 & 131,4 & 133,6 \\
\hline India & 86,5 & 93,5 & 98,5 & 99,7 & 102,2 \\
\hline Russia & 61,8 & 73,3 & 85,9 & 71,6 & 73,5 \\
\hline USA & 55,8 & 62,9 & 47,4 & 51,3 & 52,3 \\
\hline Canada & 27,6 & 30,5 & 30,0 & 32,2 & 32,3 \\
\hline Pakistan & 25,1 & 26 & 26,7 & 25,5 & 25,6 \\
\hline Ukraine & 26,5 & 26,1 & 26,2 & 25 & 29 \\
\hline Australia & 23,7 & 22,3 & 31,8 & 17,3 & 15,6 \\
\hline Turkey & 22,6 & 20,6 & 21,5 & 19 & 19 \\
\hline Sourc: & & &
\end{tabular}

Source: Wikipedia.org, Global grain production 2019, Global Market Analysis, FAS, USDA 2020

According to Table 1, the world wheat production is beginning to grow. The total world wheat production at January 2020 was 764.39 million tons [2]. The first place in the TOP-10 is occupied by the European Union, with an indicator of 154 million tons, followed by China - 133.6 million tons, India - 102.2 million tons, Russia - 73.5 million tons, USA - 52.3 million tons. , Canada - 32.3 million tons, Pakistan - 25.6 million tons, Ukraine - 29 million tons, Australia - 15.6 million tons, and Turkey completes the list with an indicator of 19 million tons. Over the past 5 years, wheat production has increased in China by 3.4 million tons, in India by 15.7 million tons, Russia by 11.7 million tons, Canada by 4.7 million tons, Ukraine 2.5 million tons However, in the United States, Pakistan, Australia and Turkey, this figure has declined. These indicators directly depend on the seasonal precipitation and soil moisture. In Australia, we can observe a decrease in wheat yields for 2018 and 2019 due to low rates of rainfall during the growing season [2].

Table 2. TOP-10 countries exporting wheat in the world for 2015-2019, million tons.

\begin{tabular}{l|c|c|c|c|c}
\hline & 2015 & 2016 & 2017 & 2018 & 2019 \\
\hline Russia & 23 & 24 & 27,184 & 32,2 & 34,5 \\
\hline EU & 28 & 27 & 28 & 28,5 & 27 \\
\hline USA & 25 & 25,7 & 26 & 26,3 & 25,86 \\
\hline Canada & 22 & 21 & 20 & 20,5 & 24 \\
\hline Australia & 18 & 17 & 18 & 18,2 & 12,5 \\
\hline Ukraine & 10 & 17,5 & 18,083 & 16,5 & 19 \\
\hline Argentina & 6 & 5 & 8 & 12 & 14 \\
\hline
\end{tabular}




\begin{tabular}{l|l|l|l|l|l}
\hline Kazakhstan & 5 & 5,8 & 6 & 7,3 & 7,5 \\
\hline Turkey & 4 & 3,7 & 4 & 4,3 & 5,1 \\
\hline India & 3 & 1,1 & 0,5 & 0,5 & 0,5 \\
\hline
\end{tabular}

Source: FAO, World Grain 2019

As can be seen from Table 2, the TOP-10 countries of wheat exporters do not include all the countries of the TOP-10 wheat producers in the world. China produces the most wheat in the world, but does not export it, as it processes it completely and uses it for its own needs. Kazakhstan is also not among the top ten wheat producers in the world, but is among the first wheat exporters in the world. It accounts for only $4.5 \%$ of world wheat exports in 2019 (see Figure 1).

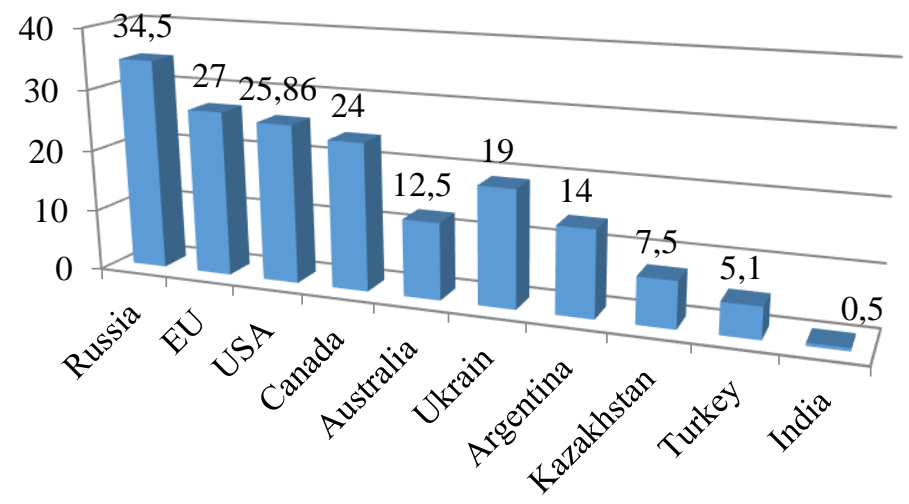

Fig. 1. Share of countries exporting wheat in the world in 2019.

Russia, the EU and the USA account for 51.6\% of world wheat exports in 2019 from 10 exporting countries as a whole. Canada, Australia. Ukraine, Argentina, Kazakhstan, Turkey and India account for $48.3 \%$ of the total number of wheat exporters in the world. Of these, Canada exports the most, accounting for $14.2 \%$ of the total exports of countries. Over the past 3 years, India has virtually stopped exporting wheat due to population growth and increasing domestic needs of the country. Argentina and Ukraine over the past 5 years have increased wheat exports by almost 2 times. Australia, on the contrary, reduced wheat exports from 2015 to $30 \%$ in 2019 . All these reasons for the growth and decline of wheat exports in the world are directly related to its production. And it is directly affected by climate change and weather conditions [3]. In addition, the era of climatic problems that will occur in certain regions will directly affect the world wheat market [4]. Despite the marketing differences of countries on pricing, wheat exporters compete in the grain market for the quality of wheat and its main indicator of the demand of other countries. It should be noted that the main export of wheat falls on African and Asian countries.

Table 3. TOP-10 importers of wheat in the world for 2012-2018 marketing year (MY), million tons.

\begin{tabular}{l|c|c|c|c|c|c}
\hline & $\begin{array}{c}2012 / 13 \\
\text { MY }\end{array}$ & $\begin{array}{c}2013 / 14 \\
\text { MY }\end{array}$ & $\begin{array}{c}2014 / 15 \\
\text { MY }\end{array}$ & $\begin{array}{c}2015 / 16 \\
\text { MY }\end{array}$ & $\begin{array}{c}2016 / 17 \\
\text { MY }\end{array}$ & $\begin{array}{c}2017 / 18 \\
\text { MY }\end{array}$ \\
\hline Egypt & 8,3 & 10,2 & 9,5 & 4,5 & 5,8 & 3,6 \\
\hline Brazil & 7,4 & 7,1 & 7,0 & 7,2 & 7,5 & 7,8 \\
\hline Indonesia & 7,1 & 7,4 & 7,7 & 2,3 & 1,7 & 2,1 \\
\hline
\end{tabular}




\begin{tabular}{l|c|c|c|c|c|c}
\hline Algeria & 6,5 & 7,5 & 7,4 & 7 & 7,3 & 7,5 \\
\hline Japan & 6,6 & 6,1 & 6,6 & 5,8 & 4,5 & 5,1 \\
\hline Iran & 6,6 & 4,8 & 5,5 & 5,8 & 7,4 & 9,7 \\
\hline EU & 5,3 & 4,0 & 5,0 & 5,3 & 5,5 & 5,8 \\
\hline Nigeria & 4,1 & 4,6 & 4,8 & 8,6 & 14 & 4,9 \\
\hline Turkey & 3,6 & 4,0 & 5,8 & 3,1 & 2,6 & 8,1 \\
\hline USA & 3,3 & 4,6 & 4,6 & 4,8 & 4,9 & 5,1 \\
\hline
\end{tabular}

Source: www.fao.org

As can be seen from table 5, the TOP-10 importers of wheat also includes exporting countries, such as the USA, EU and Turkey. Comparing export and import data, for example, of the United States, it is clear that imports account for one sixth of exports. This is mainly due to a decrease in wheat production due to an increase in the production of corn and soy. Import to the EU is due to the fact that not all EU countries are capable of producing a sufficient quantity of high-quality wheat, and German crops are not able to cover all the needs of the EU countries. Turkey has also recently reduced wheat production due to an increase in other agricultural export products, such as almonds, olives, lemons, etc. In other countries, TOP-10 importers show that they increased grain imports over the last marketing year (MY).

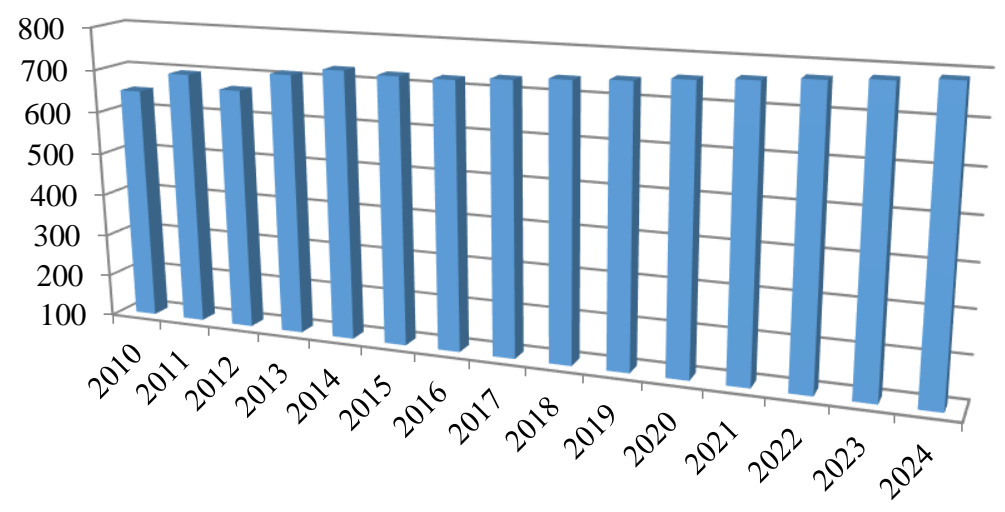

Fig. 2. The volume of world wheat production in 2010-2019 and the forecast until 2024, million tons.

Source: Wheat production in the world. Wheat producing countries // Expert and Analytical Center for Agribusiness // http://ab-centre.ru

As can be seen from Picture 2, according to experts, the wheat harvest in 2019 will be almost the same as in 2018. However, starting in 2020, the global volume of wheat will increase every year and in 2024 will reach the level of 787 million tons. Trends in the production and export of wheat in the world will be concentrated in countries such as: USA, EU, Canada, Australia, Russia and possibly Kazakhstan.

In the world there are two types of farms engaged in the production of wheat - extensive and intensive. The United States is mainly engaged in extensive farming, where the principle that wheat is produced only in regions where it is impossible to efficiently grow corn prevails, since the latter provides a significantly higher yield (in terms of starch) than wheat and has a great feed value. In the USA, it is not profitable to apply a huge amount of fertilizer and use innovative technologies in the arid steppe regions. Therefore, wheat is mainly produced in areas with good climatic conditions, because Wheat is partly a US export product. 
In Canada, wheat production is carried out in the same way and the wheat is grown in the central steppe provinces. Nevertheless, Canada pays special attention to the cultivation of hard and strong wheat varieties, the quality of which this country is number one in the world. The same situation is observed in Australia.

In the EU countries, an intensive type of production dominates, where they apply new technologies, fertilizers and are actively engaged in the improvement of wheat varieties [5].

In Russia, Kazakhstan and Ukraine, they are mainly engaged in an extensive type of farm in the production of wheat. This is a kind of natural type of farming since the days of the Soviet Union. In these countries there are a huge number of problems and shortcomings in grain production. Such disadvantages include: the lack of a unified elevator system with a high service capacity, a transport and procurement system with relevant legislative provisions, the absence of an additional system of refinement, cleaning and storage of grain, which can significantly reduce the loss of wheat in quantitative and qualitative terms. Here we should adopt a method of approach to wheat growing similar to the Canadian system, where special attention is paid to the best varieties of hard and soft wheat intended for export. The group of authors gave their recommendations for improving the territorial indicators that determine the competitiveness of regions [6]. It means that we need to develop areas that are most favorable for doing agro business, thereby expanding territorial marketing.

According to scientists, on average it is possible to increase wheat production by $10 \%$ per year by improving the quality of seeds and investing profit in centers for the selection of wheat varieties. This method is the most costly and in the future can lead to the greatest economic effect and obtain large wheat crops per year from one hectare of land. For this, it is also necessary to grow wheat in favorable regions of the country with a less arid climate, so that the wheat has time to grow and mature before the dry season.

Several foreign scholars have proposed their vision of innovation in wheat production and set forth this in their research. So J. Sherrard in his study described innovations that primarily save countries' water resources in those areas where drought-resistant wheat varieties can be produced by improving their quality in special laboratories. The creation of such wheat varieties can significantly modernize and improve grain production in Eastern Europe, sub-Saharan Africa and the southern hemisphere as a whole, where investment in infrastructure will be vital [7].

A similar method of growing wheat was proposed by H.S.Saini and M.E. Westgate. In their study, they discovered a method for the reproductive development of wheat and other crops, which during a drought will ripen due to moisture stored in the stems and leaves and thus ripen naturally in the fields. They also proposed to apply an innovative method in the production of wheat, which will retain moisture in the fields by sowing wheat in such a way that the sun's rays do not pass through the leaves and the plants themselves are fed due to morning dew, which accumulates after changes in night temperature [8].

N. Uphoff in his study immediately proposed three methods of agroecological innovation: microbiological, chemical and engineering. The first method, as well as the methods described above, involves first of all the creation of new varieties of wheat by the microbiological method, possibly crossing them with other varieties of wheat or genetically modifying them. The second method involves the creation of new fertilizers in a chemical way that will maximally provide plants with all the necessary elements for growth and reproductive life cycle, as well as the creation of chemicals against the control of wheat pests. The third method involves the creation of new automated machines for the care of wheat. This also includes facilities for sorting and storing grain. He suggests connecting all these three methods together with the economic mechanism of interaction with each other [9].

The following foreign researchers, like their previous colleagues, in their study based on selective selection of wheat, in which the greatest economic effect will be achieved by 
obtaining a larger crop. They proposed to carry out selection work through the development of special programs and centers to expand environmental and agronomic research in the world, where ever new varieties and technologies of wheat growing will be accumulated [10].

D. Sunding and D. Zilberman in their study examined the formation and implementation of new technologies in the agricultural sector using induced mutagenesis and hybridization of wheat varieties. They described the models of induced innovation and experimentation for various types of production, where the main ones will be laboratories and research centers for selection and introduction of new varieties [11].

D. Onaltayev, A. Kazhmuratova, S. Akhmetkaliyeva, R. Malikova, A. Yelyubayevabelieve that innovation in marketing is the successful implementation of new methods and techniques that are designed to improve results and increase productivity [12]. The commercialization of innovations is also indicated by a number of scientists who believe that this will bring production to a new level of development and bring corresponding profit to both developers and those who implement it [13].

D. Ben-Meir talked about technologies that can accelerate the development of new varieties of wheat and be more resistant to disease by creating a platform for exchange between agricultural producers, research centers and manufacturers of equipment for agribusiness. He suggested, like other authors, to create a center-base in which several laboratories studying the resistance of varieties to different conditions, the influence of parasites on these varieties and the susceptibility to various diseases will be located separately [14].

N. Gatti in his study gave an economic assessment of innovation, speaking about new approaches to crop production. He emphasized the technical equipment of farmers, who must have new equipment and new means of tillage and harvest [15].

K. Barlow, B. Christy, J. O'Leary, J. Nuttall examined the threats that Australia faces in wheat production. They consider wheat hybridization to be one of these threats, which ultimately differs in the number of chromosomes from the original first wheat variety and, accordingly, have different gluten protein. In addition, the paper describes some methods of controlling pests of fields for which pesticides remaining on plants after harvesting are used [16].

Ziyadin S. believes that currently favorable market conditions are emerging for Kazakhstan, which can significantly increase the export of agricultural products [17, 21]. This is due to the presence of both natural competitive advantages and the proximity of the capacious sales markets of neighboring countries. The development of the export potential of the grain industry contributes to the further diversification of the agricultural business. In the future, competition in the international agricultural market may increase, which will require significant efforts by national producers to increase the competitiveness of their products. In this regard, positioning issues must be addressed not only through the implementation of large sales volumes, but also taking into account marketing concepts for product sales [22].

\section{Methodology}

Statistical and economic analysis was used as secondary information sources. FAO reports for 2019 and 2020 on agricultural products and wheat directly were received and analyzed. The work also used the method of collecting and processing information. For this analysis, we used the publications of various scientists on innovations in agriculture and commercialization of innovations in the future. Based on this, tables and graphical charts were included. 


\section{Results and Discussion}

Thus, we can conclude that wheat variety renewal is one of the most successful ways to ensure stable and sustainable productivity of this sector of the economy. Providing farmers with the right varieties of wheat that are able to grow and produce good crops in the respective regional zones with arid regions, steppes and semi-steppes. Given the average wheat yield per hectare, which varies from 2 tons / ha to 3 tons / ha. These figures can be tripled on average, showing the example of Germany, which is not an exporter of wheat; although for its own needs, it grew 45.2 million tons of wheat in 2017, which is about 7.2 tons of wheat per hectare according to the USDA [18]. The share of Germany in the European Union in cereal production accounts for about $16 \%$, but it mainly focuses on the production of rye (more than 40\%), wheat (about 17\%) and barley (more than 18\%) [19].

The reason for this approach to growing grain and such a high yield of wheat, not only in Germany but also in France and the UK, is the strong state support. This policy is one of the branches of the Unified Agrarian Policy in the EU countries, where there are tangible differences in the methods and directions of financing agriculture in general. For example, the UK and Denmark spend 1/3 of the state agricultural budget. These expenses include modernization and improvement of farms, proposals for the use and construction of modern agricultural enterprises using new technologies and equipment of domestic producers. Considerable expenses are also spent on improving soil quality and cultivating arable land. In general, the European Union spends $10 \%$ of the agricultural budget to support novice farmers and research in crop production, as well as government programs and developments in agriculture. In the Netherlands, $30 \%$ of the country's budget is allocated for research and development.

Argentina can be attributed to the best foreign experience in the application of technologies in agriculture, since it was one of the first to apply the "Zero Tilling" technology of soil since 1975, i.e. over forty years and has achieved an increase in wheat productivity by 800 kilograms per hectare. This soil cultivation technology is considered the most developed and does not require additional tillage.

\section{Conclusion}

To summarize the above, it should be said that wheat is the main crop on the grain market in the world, since it accounts for a quarter of the world stock. The wheat market is a pivot in grain production and the main one in the development of the agricultural economy.

The structure of the world wheat market includes such major exporters as the USA, China, India, Canada, the European Union, Argentina and Australia. They also include the Russian Federation, Turkey, Kazakhstan and Ukraine.

Grain pricing will be affected by the world's final wheat stocks. The grain market has all the prerequisites for further progress in development, despite significant problems. Wheat production over the past 10 years ranged from 9.9 million tons to 22.7 million tons. Strong fluctuations in productivity and production negatively affect the export potential of countries producing wheat, which is directly related to the development of the grain industry as a whole.

World trends in the development of grain production are based on minimal tillage and an increase in arable land for growing wheat, due to which states want to increase world wheat production. The innovative basis for the production of wheat in foreign countries lies in the creation of new varieties that will be the most resistant to adverse conditions and which will produce good crops through selection and crossbreeding with other cereals [20]. It is also planned to use genetic engineering to create new varieties of wheat that will be resistant to 
pests and diseases, which account for 5 to 25 percent of losses in the production, storage and transportation of wheat.

Marketing issues in the agricultural sector are as specific as the entire production cycle of agricultural producers. In matters of marketing, a number of criteria are identified that must be taken into account when entering the market, namely:

- agricultural products are mainly in the form of raw materials for the processing industry;

- the demand for agricultural products is determined by the demand for food products obtained from agricultural raw materials;

- the demand for agricultural products forms the demand for feed, seeds and fertilizers.

Analysts' economic forecasts are based on an annual increase in demand for wheat due to an increase in the world's population and an increase in the consumption of proteins and gluten, which is obtained by processing wheat into flour and using feed wheat for poultry and livestock farms.

\section{References}

1. Food Outlook Biannual Report on Global Food Markets. Food and Agricultural Organization of United Nation. FAO (2019)

2. World leaders in the export-grain market. Food and Agricultural Organization of United Nation. FAO (2020)

3. A. Kumar, \& A. Singh, Int. J. Environ. Sci, 5(1), 73-90 (2014)

4. A. Enghiad, D. Ufer, A. M. Countryman, \& D. D. Thilmany, International Journal of Agronomy, 2017, 3931897 (2017)

5. V.I. Nazarenko, World Food Economy (2011)

6. N. A. Tovma , N. B. Shurenov, L. A. Bimendiyeva, Zh. T. Kozhamkulova, Z. B. Akhmetova. Uncertain Supply Chain Management, 8(1), 1-16 (2020)

7. J. Sherrard, To feed the world, food and agriculture industry must embrace innovation (2015)

8. H.S. Saini, M.E. Westgate, Advances in agronomy, 68, 59-96 (1999)

9. N. Uphoff, Agroecological Innovations. Increasing Food production with Participatory Development (Earthscan Publication Ltd, 2002)

10. Increased Food and Ecosystem Security via Perennial Grains (2010)

11. D. Sunding, D. Zilberman, Handbooks in Economics, 18(1A), 207-262 (2001)

12. D. Onaltayev, A. Kazhmuratova, S. Akhmetkaliyeva, R. Malikova, A. Yelyubayeva, Application of technological innovations in marketing activities of the enterprise. E3S Web of Conferences, 135, 04046 (2019)

13. L. Popova, I. Maslova, I, Korostelkina, E. Dedkova, B. Maslov, Advances in intelligent systems and computing (2019)

14. D. Ben-Meir, Potential for innovation to encourage investment in agriculture (2014)

15. N. Gatti, Economic evaluation of innovation: the case of silobags (2015)

16. K. Barlow, B. Christy, J. O’Leary, J. Nuttall, Proceedings 17th ASA Conference, 2024 (2015)

17. S. Ziyadin, Actual Problems of Economics, 136, 429-436 (2012)

18. US Department of Agriculture Official Site (USDA) (2020)

19. Germany / World Grain Forum (2017)

20. I. M. Umarov, Journal of Advanced Research in Law and Economics (JARLE), 6(13), 691-699 (2015)

21. S. Ziyadin, \& N. Kabasheva, Public Administration Issues, 5, 56-67 (2018) 
22. Mutanov, G., Ziyadin, S. /E3S Web of Conferences, DOI: $10.1051 / \mathrm{e} 3$ sconf/201913504056 (2019) 